\title{
ПРОБЛЕМЫ РЫНОЧНОЙ МОДЕРНИЗАЦИИ В ПЕРИОД НОВОЙ ЭКОНОМИЧЕСКОЙ ПОЛИТИКИ (1921-1929 гг.) (ПО МАТЕРИАЛАМ ДОНА И КУБАНИ)
}

Новая экономическая политика, принятая на X съезде РКП(б) в 1921 г. остается одной из проблемных вопросов в истории России. Интерес к ней вызван возможностью использования рыночных методов в сочетании с плановыми инструментами в ходе экономической модернизации. Проблемы переходного периода остаются актуальными и на современном этапе развития российского общества, так как важно знать и уметь использовать опыт прошлого. Экономические реформы, которые могли бы сочетать рыночные методы с политикой государственного регулирования становятся актуальными.

Уровень рыночных отношений в аграрном секторе экономики в системе нэпа определялся степенью активности государства в реализации продовольственной политики, земельных отношений и противостоянии советской власти зажиточной части крестьянства.

Новая экономическая политика на юге России, где преобладали особые формы землепользования, сформировались сословные противоречия была реализована под жестким контролем государства, которое исходило не из экономической целесообразности, а идеологических установок. Формирование новых земельных отношений, административные реформы, проводимые в течении 1920-х гг. в казачьих регионах юга преследовали цель максимального ослабления влияния казачества на приводимую политику большевиков. При этом сле- дует учесть, что уровень развития казачьих хозяйств превосходил общероссийские средние показатели. В современной исторической науке особое место отводится региональному компоненту, формированию новых исторических знаний, изучению особенностей регионов. Интерес современных историков вызывают документы, к которым доступ был ограничен по определенным попитическим и идеологическим причинам. Архивные материалы Дона и Кубани периода 1920-х гг. в настоящее время стали объектом активного изучения. Следует отметить, что после 1991 г. во многом изменились и методологические подходы, можно с уверенностью сказать, что исследователи потеряли интерес к марксистской модели новой экономической политики и во многом исследования опираются на разнонаправленные теоретические выводы в оценке нэпа.

Рыночные механизмы в системе нэпа работали под контролем государства, но не были гарантированы действующим законодательством и игнорировались по мере роста противостояния индивидуально-частных крестьянско-казачьих хозяйств и политических интересов большевиков.

Ключевые слова: новая экономическая политика рыночный механизм, казаки, земельная реформа, большевики, Кубанский округ, Донская область.

\section{PROBLEMS OF MARKET MODERNIZATION DURING THE NEW ECONOMIC POLICY (1921-1929) (ON THE MATERIALS OF THE DON AND THE KUBAN)}

The new economic policy adopted at the $X$ Congress of the RCP (b) in 1921 remains one of the problematic issues in the history of Russia. It is of interest as it provided the possibility of using market methods in combination with planned tools in the process of economic modernization. The problems of the transition period remain relevant at the present stage of development of the Russian society, as it is important to know and be able to use the experience of the past. Economic reforms that could combine market methods with government regulation policies are becoming relevant.

The level of market relations in the agricultural sector of the economy in the NEP system was determined by the degree of activity of the state in the implementation of food policy, land relations and confrontation of the Soviet power of the wealthy part of the peasantry.

The new economic policy in the South of Russia, where special forms of land use prevailed and class contradictions existed, were implemented under the strict control of the state, which did not come from economic expediency and ideological attitudes. The formation of new land relations, administrative reforms carried out during the 1920s in the Cossack regions of the South pursued the goal of maximum weakening of the influence of the Cossacks on the policy of the Bolsheviks. It should be noted that the level of development of Cossack farms exceeded the national average indicators. In modern historical science, a special place is given to the regional component, the formation of new historical knowledge, the study of regional characteristics. Modern historians are interested in documents to which access has been restricted for certain political and ideological reasons. Archival materials of the Don and the Kuban of the 1920s have now become the object of active study. It should be noted that after 1991, the methodological approaches have changed in many ways; it is safe to say that researchers have lost interest in the Marxist model of the new economic policy and, in many respects, research is based on multidirectional theoretical findings in the assessment of the NEP.

Market mechanisms in the NEP system worked under the control of the state, but were not guaranteed by the 
current legislation and were ignored as the confrontation between individual private peasant-cossack farms and the political interests of the Bolsheviks grew.

Новая экономическая политика 1921 г. для России стала определенным потрясением, пережившая с февраля 1917 г. не один экономический эксперимент в рамках деятельности Временного правительства и Совета Народных Комиссаров РСФСР. Последующая история советской системы свидетельствует о неоднократных попытках реформирования экономики с использованием рыночных механизмов, которые не были реализованы в полном объеме. В современных условиях социально-экономических преобразований, вопрос применения рыночных методов в сочетании с плановыми инструментами в ходе экономической модернизации остается актуальным для переходного периода. Опыт нэпа востребован в контексте оценки уровня и степени участия государства в этом процессе.

Последствия и исторический опыт новой экономической политики как средство модернизации экономики переходного периода, в том числе и на региональном уровне, оказались невостребованными современными политическими элитами. Однако поиск путей из социально-экономического кризиса современной России вызывает интерес к историческому опыту экономических преобразований в 1920-х гг.

Аграрный юг России с особыми условиями землепользования и сословными противоречиями в 1920-х гг. стал ареной противостояния государства и частной инициативы, в которой административно-командная система доминировала с преобладающим идеологическим влиянием. Развитие экономических отношений в современной России связано с восстановлением институтов частной собственности, активного использования частнокапиталистических методов хозяйствования, индивидуализации сельскохозяйственной деятельности, что вызывает определенные проблемы как для самого частного бизнеса, так и общества

В ходе изучения темы в научный оборот были вовлечены новые архивные материалы. Источниковая основа статьи включат в себя директивные и отчетные документы Кубанской и Донской окружной партийной организации, контролирующих и хозяйственных органов. В настоящее время уже исследован репрезентативный массив исторических источников, в котором отражены события 1920-х гг. в казачьих регионах юга России. Основная часть источников размещена в государственных архивах Ростовской области, Краснодарского края, которые были использованы при написании статьи. Наибольший интерес представляют фонды Государственного архива Краснодарского края «Кубано-Черноморский обком РКП(б)», «Кубано-Черноморская областная рабоче-крестьянская инспекция» и «Донской окружной комитет РКП(б)» Государственного
Key words: the New Economic Policy, market mechanism, Cossack, land reform, bolsheviks, the Kuban district the Don region.

архива Ростовской области. Кроме этого следует выделить следующий вид источников, характеризующий ход и последствия экономических реформ 1920-х в казачьих регионах юга России: документы хозяйственных органов управления Кубани и Дона, статистические сборники и отчёты, инорормационные сводки и обзоры. Большая часть архивных фондов 1920-х гг. стали доступны для исследователей, что позволяет активно их использовать для оценки экономических процессов периода новой экономической политики.

Состояние экономики после Гражданской войны требовало принятие экстренных мер, хотя у большевиков существовали проекты продолжения политики «военного коммунизма» способного решить, по их мнению, вопрос социалистической реконструкции.

Политические события весны 1921 г. (Кронштадтский мятеж, протестные движения крестьян в Тамбовской, Воронежской областях, на юге России) окончательно убедили большевиков о необходимости изменения экономической политики. Системные социально-политические противоречия в российском обществе до критического обострили вопрос о сохранении политической власти большевиков.

Новая экономическая политика стала необходимой мерой временного характера, которая была направлена на выведения страны из кризиса [1]. Начатая реформа в экономике не затрагивала принципиальных основ политической системы Советской власти, что в конечном итоге предопределили её итоги. Главный вопрос новой экономической политики заключался в разрешении крестьянской темы во всем его многообразии. Именно этот вопрос стоял на повестке Х съезда РКП(б), при том, что он был не основным и не первым.

Рассматривать аграрные отношения в рамках новой экономической политики лишь в аспекте решения вопроса продовольственного снабжения, передела земли, новых форм хозяйствования означало временный характер рыночных преобразований, их возможные перспективы при пассивном участии населения, которые привели в конечном итоге к установлению административно-партийной системы. Ставить вопрос о том, что было бы при сохранении базисных основ нэпа в определенной перспективе было бы нецелесообразно, так как в тех исторических условиях, в которых находилась Советская Россия по объективным причинам это было невозможно. Был ли вообще нэп, как механизм рыночной экономики, в особенности в аграрном секторе экономики, во многом определяется степенью проявлению этих признаков и ролью, и степенью участия государства. Принятие и декларирование рыночных методов хозяйствования не означало сиюминут- 
ное их внедрение. С хронологической точки зрения рыночные отношения стали проявляться с 1923 г. и связано это было с введением в оборот твердой национальной валюты, формированием государственных институтов управления экономикой и главное, преобладанием частных торговых учреждений и заготовительных организаций которые определяли свою деятельность исходя из конъюнктур рынка

В исторической исследовательской литературе вопрос о характеристике нэпа как комплекса рыночных мероприятий вызывает острую дискуссию В данном случае нас интересует как на уровне региональной экономики (Кубано-Черноморской (Кубанском округе с 1924 г.) и Донской области) реализовывались рыночные механизмы.

Наличие революционных лозунгов и установок, диктатуры как политической системы подразумевала и радикализацию содержания экономических реформ, тем более при тех объективных условиях, в которых развивалась советская экономика в 1920-х гг. [2].

Во многом результаты нэпа на Кубани и Черноморье определялись условиями землепользования, исторически сложившимся расселением, формированием населенных пунктов. Немаловажным фактором давления со стороны Советской власти на казачество было и административное реформирование. По состоянию на 1 октября 1924 г. в округе проживало 1.300 тыс. чел на территории 3.695 тыс. га (3.389 тыс. дес.). Административная реформа, проеденная в 1924 г. оказала существенное влияние на ход реформ в сельском хозяйстве. Одной из главных проблем для округа была многодворность. В округе населенных пунктов с численностью населения от 10.000 до 12.000 чел. насчитывалось 24 (20\% от общего числа населенных пунктов); численностью от 13.000 чел. до $16.000-9(10,3 \%)$; численностью от 7.000 до 10.000 чел. 25 (16,7 \%) Как видно из приведенных данных, на поселения с числом жителей от 7 тыс. до 13 тыс. приходилось до 38 \% всего населения, проживавшего в 58 населенных пунктах из общего их количества 597

После проведенной административной реформы Кубанский округ был разделен на 18 районов каждый размером до 200 тыс. га. при средней плотности населения 30,7 чел. на один квадратный километр в сельской местности.

Административному ресормированию подвергался и Донской округ. После установления Советской власти на Дону в 1920 г. Область войска Донского была переименована в Донскую область с центром в Ростове-на-Дону. Область состояла из Ростовского, Сальского, Черкасского, 1-го Донского, Верхне-Донского, Донецкого, Усть - Медведницкого, Хоперского, 2-го Донского и с 1921 г. Морозовского округов. В апреле 1921 г 2-й Донской, Усть-Медведицкий и Хоперский округа вошли в состав Царицынской губернии на основании декрета ВЦИК от 04.04.1921 «О включении в состав Царицынской губернии станиц и волостей Донской области». В марте 1923 г. было утверждено новое административное деление
Донской области, в результате которой область объединила следующие округа: Сальский, Морозовский, Черкасский, Ростовский, 1 Донской и Донецкий. В июле 1924 г. Донская область как административная единица была упразднена. В результате районирования её территория была разделена на 4 округа: Ростовский (вскоре переименована в Донской), Сальский, Морозовский, Донецкий. Округа непосредственно подчинялись Юго-Восточному краю.

Особое значение на юге России имели формы землепользования и распределение их по назначению. В Кубанском округе из общего фонда земли до $71 \%$ приходилось именно на пашню, что и определяло весь уровень развития сельского хозяйства. В результате проведенной реформы за период с 1921 г. по 1924 г. сельские общины получили значительное приращение в размере 780 тыс. га., а местные Советы владели резервом в 277 тыс. дес. Обеспеченность землей населения Кубанского округа из расчета на одно казачье хозяйство характеризовалось следующими данными: многоземельные от 28 до 33 га., к которым относились Горяче-Ключевской, Покровский районы и малоземельные от 6,5 до 9,7 га Лабинский, Крымский районы. Притом что удобной земли в округе было 2.946,5 дес., а неудобной 442,9 дес. Обеспеченность населения землей из расчета на одну душу населения составляла 2,3 дес. земли $[4$, л. 130].

К 1924-1925 гг. землеустроительные работы были завершены на площади 1543.484 га. Это позволяло выделить достаточно большому количеству безземельных хозяйств наделы, провести мероприятия по расселению крупных станиц с целью решения вопроса дальноземелья, создание групповых отрубов и единоличных хозяйств. Социальные последствия этих мероприятий имели большее значение чем перераспределение земли. Эта политика приводила к размыванию казачьего сословия и лишала их преимуществ перед иногородними и крестьянами. Статистическая динамика с 1916 г. по 1925 г. свидетельствует о последовательном росте крестьянских хозяйств: 1916 г. 187.556 хозяйств; 1920 г 200.740 хозяйств; 1923 г. 227.504 хозяйств; 1924 г. 234.624. Количество крестьянских хозяйств увеличилось на 47.068 единиц без учета переселенцев из южных губерний центральной России в количестве 4.390 хозяйств из расчета 5,1 душ на каждое хозяйство. Притом, что за этот период поголовье лошадей сократилось с 492.439 в 1916 г до 346.305 в 1924 г. Таким образом в среднем на одно хозяйство приходилось менее одной лошади, а нагрузка на лошадь составляла до 8,5 дес. земли, в то время как в 1916 г. нагрузка составляла 3,4 дес. При такой оснащенности сельскохозяйственное производства не могло рассчитывать на интенсивное развитие и эффективное использование рыночных механизмов [5, л. 64] Это был удел зажиточных казачьих хозяйств, использующих аренду земли, наем рабочей силы и способные реализовать товарную продукцию на местном рынке. Большинство зажиточных 
казачьих хозяйств владели мельницами, маслобойнями, торговыми лавками, могли предоставлять товарную или денежную ссуду, арендовать дополнительные земельные наделы. Выборочный характер применения рыночных методов в сельском хозяйстве Кубанского округа не мог удовлетворить потребности государства в продовольствии. В критических ситуациях при сборе продовольственного налога государство использовало административно-политические методы (силовые), игнорируя действующее законодательство. Это была одна из главных причин, которая привела к преждевременному завершению экономических реформ

Нарастающий новый слой предпринимателей, нэпманов не был гарантирован государством с точки зрения имущественных и политических прав. Противоречия периода нэпа, где применялись директивно-плановые методы в сочетании с рыночными провоцировали кризисы, которые повторялись ежегодно и в основе их был аграрный вопрос.

Восстановление основных показателей сельского хозяйства Кубанского округа и Донской области во второй половине 1920-х гг. не свидетельствовало о качественных изменениях в сельском хозяйстве, в первую очередь - качественном росте производительности труда. Относительное увеличение посевных площадей в Кубанском округе за период с 1920 г. с 900.000 дес. до 1.211.200 дес. в 1924 г. (1916 г. 1.369.990 дес.) было связано с ростом посевов технических культур [6, л. 132].

Основные показатели развития сельского хозяйства Кубани и Дона 1924 г. уступали контрольным цифрам 1916 г., кроме роста населения и числа казачье-крестьянских хозяйств. Казачье хозяйство по своему характеру представляло натурально-потребительское, неспособное к саморазвитию. Содержание проводимых реформ противоречили друг другу, с одной стороны, земельные мероприятия, основанные на принципах равенства, а с другой - внедрение рыночных механизмов. Государство выступало в интересах перевода индивидуально-крестьянских хозяйств в систему коллективных форм хозяйствования и одновременно, дозированно использовало рыночные механизмы стимулирования. Политика экономического либерализма не выдержала конкуренции с формирующейся административно-командной системой, где доминировали идеологические установки.

За период с 1920 г. по 1924 г. количество без посевных хозяйств в округе уменьшилось с 29,7\% до $15,1 \%$ при росте середняцких хозяйств с 30,5 до $38,8 \%$ и при относительно стабильном положении роста кулацких хозяйств от 15,5 \% до $14,5 \%$ за указанный период $[7$, л. 2].

Первая половина 1920-х гг. характеризуется ростом населения и числа крестьянских хозяйств при одновременном снижении числа сельскохозяйственного инвентаря и домашнего скота. Последствия периода 1914-1920 гг., голода 1921 г., сокращение рынка сбыта, земельная политика большевиков привели к снижению размеров казачьих хозяйств и формированию натурально-потребительского хозяйства.

Новая экономическая политика представляла собой комплекс практических, в том числе социально-экономических и культурно-идеологических мероприятий, нежели государственно-правовую концепцию развития на перспективу, что во многом предопределило дальнейшую судьбу нэпа. Новая экономическая политика, как альтернатива регламентированному планированию могла найти практическое применение в последующем, но только не в период послереволюционных событий и когда у власти находилась первая волна руководителей, состоящих из революционеров, воспринимающие реформы как продолжение революции, но в ином формате. Нэп был возможностью модернизации всего комплекса социально-экономических и общественных отношений, но не был реализован из-за идеологических установок и экономической целесообразности.

Ставка на хозяйственного мужика не должна была истолковываться как возможность политической реабилитации кулака. Гарантией сохранения политической диктатуры большевиков служили конституционные ограничения для той социальной группы, которая сформировалась в годы нэпа - нэпманы.

Состояние стагнации в сельском хозяйстве, связанное с низкими темпами восстановление посевных (зерновых культур) площадей, поголовья тягловой силы, сельскохозяйственного инвентаря с достаточной определенностью характеризовали и направления тенденций развития сельского хозяйства юга России. При всех экономических конъюнктурах казачьи хозяйства проявляли определенную долю приспосабливаемости и выживаемости. В частности, отсутствие легального сколько-нибудь развитого рынка вызвало сокращение промышленных культур и мясного продуктивного скота. Крепкие хозяйства в силу объективных причин сокращения рабочего скота, наемного труда сокращали площади под зерновые культуры, которые компенсировались развитием (ростом) огородничества, бахчеводства, имеющие в условиях юга тенденцию исключительно потребительский характер.

Рыночный оборот продукции сельского хозяйства в значительной части являлся результатом снижения потреблении сеющего населения и расходования основного капитала. Возможность капитализации при таких условиях была чрезвычайно сложной. Такое могли себе позволить наиболее зажиточные хозяйства. Благоприятные перспективы относительно развития площадей посевов, хорошие урожаи трех лет (1922-1924 гг.), осложнились значительным снижением сева озимых в 1925г., уменьшением поголовья рабочего скота, что было связано с неблагоприятными рыночными конъюнктурами 1923 г. Высокий уровень налогообложения легли основной тяжестью на середняцкие хозяйства Кубани и Дона.

Эволюция сельского хозяйства 1922-1924 гг характеризовалась интенсивным развитием 
посевных площадей, что объяснялось с одной стороны сокращением числа без посевных как результат землеустроительных работ, а с другой стороны значительным оживлением зажиточной части казачества в виду расширения рыночных отношений.

Осенью 1923 г. в стране разразился «кризис сбыта». При хорошем урожае крестьяне не имели возможность реализовать свою продукцию из-за низких цен на зерно и высоких на промышленные товары. Деревня стала задерживать сдачу хлеба по продналогу, а по стране прошли массовые выступления рабочих и крестьян. Государство вынуждено было пойти на уступки крестьянско-казачьей массе. В этот период произошли изменения в ценовой политике, была разрешена аренда земли и использование наемного труда Немаловажным стимулирующим фактором развития крестьянского хозяйства был перевод продналога на денежный эквивалент в 1924 г. Данное решение стимулировало рост товарно-денежных отношений в аграрном секторе. Однако поддержка не рентабельных бедняцких хозяйств в рамках проводимой социально-ориентированной политики не способствовало поступательному развитию крестьянско-казачьих хозяйств. Своеобразный культ бедности сопряженный с социальными обязательствами большевиков как последствие социалистической революции не мог поддерживать рыночные методы хозяйствования, так как в основе были политические и идеологические установки, а не экономическая целесообразность.

Предоставляя беднякам льготы при получении кредитов, при выплате налогов, снабжая их посевным материалом, сельскохозяйственным инвентарем государство не получало экономических дивидендов. При этом государство оказывало давление на хозяйства зажиточных казаков кулаков за счет дополнительного налогообложения. По отношению к этим хозяйствам проводились уравнительные переделы земли, изымались, так называемы излишки земли, в пользу бедняцких хозяйств, что снижало их мощности и урожайность.

К середине 1920-х гг. наблюдался качественный перелом в сельском хозяйстве. Вместо крепких казачьих хозяйств (кулацкие хозяйства) общее количество которых было не столь велико черты товарного хозяйствования приобретают середняцкие хозяйства. Одновременно растет количество коллективных советских хозяйств [8, л. 130-134]. Политика "ограничения кулачества» стало причиной снижения во второй половине 1920-х гг. товарности крестьянских хозяйств, их рыночной ориентации. По сравнению с довоенным уровнем, сократилась доля продукции, направляемой крестьянами на внутренний рынок. В 1926-1927 гг. крестьянские хозяйства Советской России потребляли до 85 \% производимой продукции, что означало возврат к натуральному хозяйству. Отсутствие льготных кредитов, диспропорция цен на промышленные и сельскохозяйственную продукцию отрицательно влияли на развитие крестьянско-казачьих хозяйств. Дпя сельского хозяйства Кубанского округа было характерно, что 50 \% произведенной продукции селяне оставляли для собственного потребления

Рыночный оборот сельского хозяйства Кубанской области в 1924-1925 гг. был оценен в 21 млн руб. в то время как в 1916 г. этот показатель достигал 50 млн руб. Восстановление сельского хозяйства к середине 1920-х гг. не произошло, а состоялся относительный рост числа крестьянских хозяйств, ориентированных на собственное потребление.

Сельское хозяйство юга России к середине 1920-х гг. приобретало явно выраженные черты натурально-потребительского свойства. Крестьяне не были заинтересованы в расширении производства зерна и сырья для промышленности из-за постоянной инфляции [3].

Одновременно государство шло к очередному заготовительному кризису 1928-1929 гг.

Государство постоянно находилось в состоянии двойственности, когда с одной стороны сельское хозяйство основанная на индивидуально-частном хозяйствовании, а с другой, промышленность в большей части действующая на принципах государственной собственности и планово-распределительных принципах привели в конечном итоге к победе плановости и формированию административно-командной системы

Тенденции развития региональной промышленности напрямую зависели от уровня развития сельского хозяйства. Вместе с тем многое определялось и промышленностью, так как темпы её восстановления влияли на развитие внутреннего рынка потребления. Наиболее полное состояние Кубанской промышленности дает учет предприятий, проведенный в 1920 г. В этот период было зарегистрировано 4500 предприятий. Две трети предприятий размещались на территориях сельских поселений. Промышленность округа представлена была преимущественно обрабатывающей отраслью. Наибольшее количество крупных предприятий располагались на территории Лабинского и Краснодарского районов.

Ведущей отраслью были пищевкусовая, представленная маслобойными и мельничными предприятиями. В этих отраслях насчитывалось 1242 предприятия. Большое значение имела степень распространения среди различных групп предприятий механических двигателей. На 1182 предприятиях применялись механические двигатели, в том числе на 692 (58 \%), усовершенствованные механические двигатели, в основном в производстве пищевых продуктов. Следует отметить, что промышленные предприятия с механическими двигателями в большинстве своем располагались в сельской местности. На долю пищевкусовой промышленности приходилось свыше $31 \%$ всех занятых рабочих в Кубанской промышленности. Промышленность области по структуре и техническому состоянию относилась к категории мелкой, кустарно-ремесленного типа. К моменту районирования, т.е. к 1 октября 1924/1925 гг. состояние промышленности характеризовалось следующими показателями: государственных 
предприятий 54, из них в состоянии производственного цикла 46, с числом рабочих 3.667 раб., производящая валовую продукцию на сумму 1.363. тыс. руб. Кооперации на правах собственности принадлежало 4 предприятия с числом рабочих 218 чел., производящую продукцию на сумму 113.841 руб.; в арендном пользовании находилось 10 предприятий с числом работающих 233 чел., с производительностью 151.232 руб. В арендном пользовании у частных арендаторов находилось 47 предприятий с числом рабочих 844 чел., производившую продукцию на сумму 733.068 руб. Итого 115 предприятий с числом работающих 4.962 чел. производили продукцию на сумму 2.361.141 руб. Но при этом следует отметить, что на арендованных предприятиях выработка на 1-го работающего составляла 1.172 руб. в год, в то время как на государственном предприятии 419 руб.

Развитие местной промышленности в середине 1920-х гг. имело тенденцию роста числа работающих предприятий за счет сдачи их в аренду, сокращение рабочих, роста безработицы при незначительном увеличении заработной платы.

Стоимость продукции цензовой промышленности 1924-1925 гт. при тенденции сокращения промышленного производства составляла $13 \mathrm{Mлн}$ руб. (в 1916 г. 20 млн руб.) [9, л. 136]. По экономическим показателям уровень её развития во многом отставал от довоенных показателей: объем произведенной продукции в 1923 г. был равен $40 \%$, а в 1924 г. это соотношение достигло $60 \%$.

Промышленность Донской области состояла из трестированных, кустарной и арендованных предприятий. Кустарные предприятия по объему производства превосходили арендованные, но уступали трестированной, производя лишь $3 \%$ от их общего объема. Торговый оборот Донской промышленности за 1924-1925 гг. составлял 35.381.860 руб. Неразрешимой задачей для местной промышленности, как и для Кубанской, оставался рост производительности труда при стабильной заработной плате [10, л. 66]. После либерализации арендных отношений в Донской области произошел рост аренды земли, где основными арендодателями выступали бедняцкие хозяйства. Арендные отношения развивались не в пользу бедняцких хозяйств. Большинство договоров предусматривало натуральную фрорму оплаты при низкой ставке арендных выплат. Рост товарно-денежных отношений в станицах Дона был ограничен неразвитостью рынка и ростом натурализации казачьего хозяйства. В Донской области при сокращении мало посевных хозяйств не произошло качественного изменения в общей структуре аграрных отношений. Большой процент хозяйств, не имевших сельскохозяйственный инвентарь, живой тягловой силой вел к качественному упадку сельскохозяйственного производства [11, л .73]. В сельской местности было сосредоточено 72.624 сельскохозяйственных батраков, что составляло 30 \% от общей массы трудоспособного населения Дона [12, л. 65]. Агарный сектор экономики не справлялся с рын- ком рабочей силы, что провоцировало рост социальной напряженности, основанный на имущественном неравенстве в большей степени, чем на сословных противоречиях. Это отрицательно сказывалось на общем уровне развитии крестьянско-казачьего хозяйства и провоцировал властные структуры на игнорирование рыночных законов и перехода на административные методы руководства.

Исходя их данных о состоянии основных и оборотных капиталов местной государственной промышленности, следует отметить, что интенсивного восстановления, разрушенного Гражданской войной промышленности не было. Продукция местной промышленности характеризовалась высокой стоимостью продукции по сравнению с продукцией сельского хозяйства, что приводило к затовариванию предприятий.

Следует отметить незначительный рост производительности труда на предприятиях местной промышленности. При этом продолжался рост числа безработных, так шел неконтролируемый приток рабочей силы из станиц. (последствия кризиса 1921 г.)

Для 1922-1923 г. характерно снижение цен на продукцию сельского хозяйства. Этот год являлся последствием предшествующего периода время чрезмерной высокой стоимости продукции сельского хозяйства относительно цен на промышленные товары. Это был период диктатуры хлеба. А период 1923-1924 гг. характеризовался обратным процессом. Расхождение цен на продукцию сельского хозяйства и промышленности на юге России было значительное, чем по всему Союзу CCP.

Нэп в сельском хозяйстве, как рыночный механизм не решил главной задачи повышение товарности, производительности труда, развитие торговых отношений с городом. Крестьянско - казачье хозяйство, решив частично проблемь личного потребления не смогло разрешить возложенные на него производственные проблемы. В противостоянии плановых и рыночных механизмов в системе новой экономической политики рынок уступил. Уровень развития рыночных отношений был минимизирован в рамках продовольственной политики большевиков

Нэп был долгосрочной экономической политикой постепенного строительства социализма. Главенствующая роль в экономических преобразованиях принадлежала государству, выполнявшую регулирующие и контролирующие функции. В системе многоукладной экономики переходного периода и при том уровне кризиса, в котором она находилась в 1921 г. эти меры носили вынужденный характер. Задача, которая была поставлена перед всем комплексом экономических преобразований, состояла в том, чтобы в максимально сжатые сроки достичь довоенных показателей в промышленности и сельском хозяйстве, снизить социальную напряженность в обществе. Дальнейшая политика по модернизации экономики вылилась в политические дискуссии в большей части связанные с борьбой за политическое ли- 
дерство. Противоречия нэпа, которые провоцировали ежегодные социальные и экономические кризисы были основаны на противостоянии рыночного начала и плановых мероприятий в системе советской власти. По мере приближения к решению вопроса об индустриализации эти про- тиворечия обострялись. Неразвитость рыночных методов хозяйствование, администрирование экономических процессов, отсутствие политических гарантий для определенного круга предпринимателей в городе и деревне предопределили судьбу нэпа.

\section{Источники и литература}

1. Бакшеев А. И. Проблемы советской государственности в Сибири периода НЭПа. Красноярск: Сибирский федеральный униреситет, 2013. 345 с.

2. Дэй Р. Б. Лев Троцкий и политика экономической изоляции. М.: «Дело», РАНХ и ГС, 2013. 182 с.

3. Мау В. А. Государство и экономика: опыт экономических реформ-М.: «Дело», РАНХ и ГС, 2017. 25 с.

3. Государственный архив Краснодарского края. (далее - ГАКК). Ф Р.990. Оп.2. Д. 67.

4. ГАКК. Ф Р.990. ОП.2. Д. 549.

5. ГАКК. Ф Р.990. Оп.2. Д. 67.

6. Центр документации новейшей истории Краснодарского края (далее - ЦДНИ КК). Ф1. Оп.1. Д.85.

7. ГАКК. Ф Р.990. ОП.2. Д. 67.

8. ГАКК. Ф Р.990. Оп.2. Д. 67.

9. Цент документации новейшей истории Ростовской области (далее - ЦДНИ РО). Ф.5. Оп.1 . Д.54.

10. ЦДНИ РО Ф.5. Оп.1. Д.52.

11. ЦДНИ РО Ф.5. Оп.1. Д.88.

\section{References}

1. Baksheev A. I. Problemy sovetskoj gosudarstvennosti v Sibiri perioda NEPa. (Problems of Soviet Statehood in Siberia during the NEP). Krasnoyarsk: SFU publ., 2013. 345 p. (In Russian).

2. Dej R. B. Lev Trockij i politika ekonomicheskoj izolyacii (Leon Trotsky and the Policy of Economic /solation). Moscow: «Delo» RANE and PS publ., 2013. 182 p. (In Russian).

3. Mau V. A. Gosudarstvo i ekonomika: opyt ekonomicheskih reform (State and Economy: Experience of Economic Reforms). Moscow: «Delo» RANE and PS publ., 2017. 25 p. (In Russian).

4. State archive of Krasnodar region. (GAKK). F.R. 990. Inv.2. D. 67. (In Russian)

5. GACC. F. R. 990. Inv.2. D. 549. (In Russian).

6. GACC. F. R. 990. Inv.2. D. 67. (In Russian).

7. The documentation centre of recent history in Krasnodar region (Center for KK). F1. Inv.1. D. 85. (In Russian).

8. GACC. F. R. 990. Inv.2. D. 67. (In Russian).

9. GACC. F. R. 990. Inv.2. D. 67. (In Russian)

10. Cent of documentation of the modern history of the Rostov region (CDNI RO). F. 5. Inv.1. D. 54. (In Russian)

11. CDNI RO. F. 5. Inv.1. D. 52. (In Russian).

12. CDNI RO. F. 5. Inv.1. D. 88. (In Russian) 